\title{
A Firmer Grounding
}

\section{Peter Hill, St George's Hospital Medical School and Helena Waters, Institute of Psychiatry}

The great leap forward from trainee to consultant ends with one well-grounded foot. Clinical training to current standards provides the novitiate with a firm base as far as taking clinical responsibility. Responsibilty for maintaining or developing service and the profession is another matter, and in this respect too many newly-appointed consultants find themselves with their other foot in a quagmire, at risk of being bogged down in administration. One foot that has received solid grounding is not enough to hit the ground running. Actually, the stumble goes unnoticed as often as not. Dead-end committee posts are hived off on to the new appointee and no-one remarks on his silence at table or the failure to grasp the politics of administration. Some, of course, take to the mud with squeals of glee, throwing their weight around without moving from the spot. Some colleagues get spattered. Some sink. No progress ensues. There may then evolve a distaste for administration, a spurning of bureaucracy, truancy from the Division (can there be worse?) and rotting relationships with hospital administrators. Does it matter? Surely people find out soon enough how the system works; if you can run a group you can chair a committee; individuals make better decisions than committees and nobody listens in any case.

Well, if it did not matter in the past, it will soon. With the contraction to District level services, the capacity for health services to plan ahead for Cinderella services is going to be restricted by the major acute medical specialties clamouring for resources. The smaller the administrative unit, the louder in relative terms the clamour will be. Smaller budgets and a tendency to concentrate on the District General Hospital means an increasing squeeze for community-based services, distant mental hospitals, joint provision for mental handicap, and so on. Ironically, that is the way many administrators think towards the provision of such services. However, they too go under in the face of professional demand for a new suite of operating theatres. Pity the DMT!

We thought it plainly limp that so few psychiatric training schemes pay any attention to management skills. The contrast with nursing training is stark. There has always been occasional consultants who have made the point of giving their juniors a buzz from their bonnet-bound bees about matters administrative. Apart from that, nothing much systematic has evolved beyond the usual King's Fund residential course for senior registrars and newly-appointed consultants. Only a few psychiatrists take these up and they are heavily over-subscribed.

What we wanted to develop was a brief-very briefcourse to provide just enough for the trainee to develop a positive attitude to administration, just enough to know what skills are relevant and just enough for a minimum level of skills to be achieved. We discussed and discussed; not just with psychiatrists but with management trainers, the King's
Fund College and the DHSS. Then we put it to the test. We have run three two-day courses under the auspices of the British Postgraduate Medical Federation. These followed a pilot course devised in consultation with management consultants and run by them for senior registrars in the Maudsley Hospital. Each course since then has been run with the help of one of their number, Shirley Otto, a psychologist with particular experience in management training.

Evaluation at close and at follow-up several months later has led to us refining the package offered. We have been encouraged to learn that participants find the courses enjoyable as well as informative, and that their appreciation of individual components was consistent course by course. Experiential exercises are essential in exposing mistaken assumptions. Among the exercises selected, committee simulation or group decision games demonstrate participatory skills and emphasize chairing techniques. These are supplemented by short didactic inputs on styles of chairing, ways of making meetings effective (there is a magnificent John Cleese film on this), and on communication skills between participants. We have recently supplemented exercises on communication with video feedback of participants' behaviour during committee simulations.

On the whole we have tried to limit didactic instruction, yet there is information to be transmitted and issues to be defined. Within our time limits we cannot presume to solve the problems of everyday multidisciplinary teamwork, yet it seems helpful to clarify what the issues are, whether by group exercise or discussion. Most particularly there is a task of explaining the structure of health service administration and the implications of imminent reorganization. Most trainees know almost nothing of such matters. Indeed, it is startling to discover how many consultants are unaware how little their trainees know. Surely it is not enough to assume that they will pick it up as they go along. A quick glance to see who attends many committees suggests that many people do not go along, or if they do they merely go along with the drift of more intentioned members. No way to develop a profession, no way to develop a service.

What we have learned ourselves is how interested so many trainees become in the system once they have been through our brief two-day course. Our follow-up information strongly suggests that they involve themselves more in management areas and that they want more training, more information on a more advanced basis, so very different from some newly-appointed consultants reacting nihilistically to the demands of obscure administrative practice to which they come unprepared. From a partisan standpoint we feel some exposure to such demands and the information and skills needed to cope with these should be a requirement of higher psychiatric training. 